\title{
Análise da usabilidade conforme as recomendações da norma ISO 9241 - Um estudo de caso
}

\author{
Usability analysis according to the standard of recommendations ISO 9241 - A case study \\ - Giorgio Gilwan da Silva \\ Univali, Florianópolis \\ giorgiogilwan@univali.br \\ - Marília Matos Gonçalves \\ Ufsc, Florianópolis \\ marilinhamt@gmail.com \\ - Robson Freire \\ Univali, Florianópolis \\ robson.freire@univali.br \\ - Guilherme Sauthier
Univali, Florianópolis
guilherme.sauthier@univali.br
}

\begin{abstract}
This study investigates Trello's application interface usability, together with users, in accordance with ISO 9241, part 10. Quantitative, exploratory and descriptive research were used and the sample itself consisted of 6 design professionals. The questionnaire was formulated aiming towards finding the application's strengths and weaknesses, according to the principles: Suitability to the task; Self-description; Controllability; Accordance with the Users Expectations; Error Tolerance; Support to Individualization and Learning Suitability. The evaluation of the application usability obtained a high degree of use satisfaction for achieving effectiveness, for the system's resources efficiency and for the user satisfaction in finding easy ways to use every tool the system offers.
\end{abstract}

Keywords: Usability, Interaction, Application, Mobile

\section{Introdução}

Os responsáveis pelo desenvolvimento de produtos devem pensar na interface do sistema, com a qual o usuário interage, ou seja, a maneira como entende o significado dos ícones e o modo como vai acessar os componentes de controle e executar a tarefa. É na interface com os produtos, que podem ocorrer os principais problemas de usabilidade, levando muitas vezes, ao abandono de algumas funções importantes, por demora, erros e perda de eficiência e eficácia. O design de interação utiliza padrões ergonômicos, assim essa facilidade em compreender a interface é obtida com a usabilidade, definida por Cybis; Betiol; Faust (2007, p.23) como "a qualidade que caracteriza o uso de um sistema interativo". Segundo este autor, a usabilidade para o design destas interfaces está relacionada com a facilidade de aprendizado, a eficiência para uso, a memória, a redução dos erros, satisfação subjetiva, entre outros. No entanto, a competitividade dos produtos pode ser comprometida, quando estes não forem interativos ao usuário e de fácil acesso, sendo capazes de atendê-los de maneira eficiente. Estes problemas ocorrem com muita frequência, muitas vezes um sistema de informação é conhecido pelos usuários quando já está em funcionamento, isto pode gerar a existência de uma desconexão entre as necessidades e expectativas dos usuários e as dificuldades encontradas para acessar à informação. Dado o exposto, objetiva-se investigar junto a usuários a usabilidade do aplicativo Trello, avaliando a sua conformidade (software) com as recomendações constantes da parte 10 da norma ISO 9241 (PRINCÍPIO DE DIÁLOGOS).

A justificativa gira em torno da importância em estabelece à relação entre um design e seus consumidores, o que sem dúvida torna necessário pensar na interface entre produto/ usuário/sistema e contexto de uso. Neste sentido, a usabilidade e seus princípios podem ser aplicados como recomendações gerais, independentemente da técnica específica de diálogo que tenha sido adotada no projeto de design da interface, bem como uma alternativa para inovação e diferenciação dos produtos, como os aplicativos para dispositivos móveis. Para tanto, a usabilidade será abordada como suporte ao desenvolvimento de projeto de design, mais especificamente na potencialização da eficiência, eficácia e satisfação dos usuários na interação com o produto. No que se refere ao uso dos aplicativos, estes podem ser parte integrante de todas as empresas independente da sua dimensão, pois o alcance de benefícios é muito grande, com a tendência de sempre aumentar. Dessa forma, os aplicativos móveis podem ser usados como estratégia para projetos de design pela facilidade do acesso à banda larga em telefones celulares e tablets.

Foi utilizada a pesquisa quantitativa e exploratória nos limites de estudo de caso, com o uso do aplicativo Trello e a pesquisa quantitativa e descritiva do embasamento teórico. A amostra da pesquisa contou com 6 (seis) usuários deste 
aplicativo. Os procedimentos metodológicos contemplam: 1) definição e organização das fontes de pesquisa, das bases teóricas e metodológicas; 2) fundamentação teórica - leituras exploratórias e interpretativas; 3) estudo de caso - Aplicação do questionário com questões dos padrões de usabilidade no que se refere às percepções do usuário e as formas dos dispositivos de acesso e de comunicação com o sistema; 5) tabulação dos dados; 6) Análise e Apresentação dos resultados. Na fundamentação teórica contextualizam-se os conhecimentos sobre: design de interação e interface, padrões ergonômicos e princípios de usabilidade. Inicia-se a fundamentação teórica abordando o design de interação e interface.

\section{Design de interação e interface}

Os consumidores interagem com muitos produtos para realizar tarefas. O objetivo do design de interação consiste em desenvolver produtos interativos que possam ser compreendidos e fáceis de usar. Preece; Rogers; Sharp (2007, p.27) conceituam o design de interação como: "Design de produtos interativos que fornecem suporte às atividades cotidianas das pessoas, seja no lar ou no trabalho". A interação é um processo que engloba as ações do usuário sobre a interface de um sistema, e suas interpretações sobre as respostas reveladas por esta interface (SOUZA et al., 1999).

A interface é a parte de um artefato que permite a um usuário controlar e avaliar o funcionamento deste artefato através de dispositivos sensíveis às suas ações e capazes de estimular sua percepção. No processo de interação usuáriosistema a interface é o combinado de software e hardware necessário para viabilizar e facilitar os processos de comunicação entre o usuário e os produtos. A interface entre usuários e sistemas computacionais diferencia-se das interfaces de máquinas convencionais por exigir dos usuários um maior esforço cognitivo em atividades de interpretação e expressão das informações que o sistema processa (NORMAN, 2002).

O processo de design de interação é composto por quatro atividades básicas centradas no usuário, como destacam os autores, Preece; Rogers; Sharp (2007, p.33): a) Identificar necessidades dos usuários e estabelecer requisitos; b) Desenvolver designs alternativos que preencham requisitos; c) Construir versões interativas dos designs, de maneira que possam ser comunicados e analisados; d) Avaliar o que está sendo construído durante o processo. Estas atividades se relacionam e compartilham as informações entre si. De acordo com estes autores o foco deve ser sempre no usuário, com as metas de usabilidade e interação devidamente definidas.

O design do produto será interativo se realmente for concebido com foco no usuário e a partir da ideia do produto, for construindo versões deste produto (protótipos) e validado junto a potenciais usuários, antes de seguir para as etapas de produção.

Portanto, as interfaces dos sistemas é que devem permitir o diálogo com os usuários, facilitando a comunicação das informações e dos procedimentos a serem executados. Esta visão sobre a interface e o usuário é pertinente a presente pesquisa, uma vez que pode colaborar com a ergonomia e usabilidade deste produto e, se for o caso, melhor a relação do usuário com a interface do aplicativo Trello como contextualizado em seguida.

\section{A norma NBR 9241-11}

A norma da ISO 9241-11 definiu oficialmente o conceito de usabilidade. A usabilidade é definida como "a capacidade que um sistema interativo oferece a seu usuário, em um determinado contexto de operação, para a realização de tarefas com eficácia, eficiência e satisfação em um contexto de uso específico". A estrutura da usabilidade está diretamente ligada ao diálogo entre o usuário e o sistema em um contexto de uso, sendo intermediadas por uma interface, cujo objetivo deve ser obtido com eficácia, eficiência e satisfação. Na norma da ISO 9241, a usabilidade e seus compostos utilizam as seguintes definições:

Eficácia - Permite que o usuário alcance os objetivos iniciais de interação. Pode ser avaliada, quando uma tarefa é finalizada, em termos de qualidade do resultado esperado com o uso do produto. A avaliação da eficácia do aplicativo é feita por meio da resposta das questões:

Eficiência - Refere-se à quantidade de esforço e recursos necessários para se chegar a um determinado objetivo. Os desvios que o usuário faz durante a interação e a quantidade de erros cometidos pode servir para avaliar o nível de eficiência da tarefa ou da interação com o produto.

Satisfação - Alcançada com a ausência do desconforto e atitudes positivas para com o uso de um

Produto. O aplicativo deve proteger o seu usuário de possíveis erros de entrada e situações indesejáveis, ou seja, proteger o usuário de danos e frustrações em situações potencialmente danosas aumenta o nível de alerta; previne o erro e se, mesmo assim, ele ocorrer, permite recuperação.

Contexto de Uso - Aplica-se a usuários, tarefas, equipamentos (hardware, software e materiais), e aos ambientes físico e social no qual o produto é usado.

Como pode ser constatada, a usabilidade de um produto não é medida apenas pelas características do próprio produto, mas também pelas circunstâncias específicas nas quais um produto é utilizado. Estas estruturas indicam a satisfação do usuário do produto, que pode ser medida por meio dos princípios da norma ISO 9241.

\subsection{Princípios da Norma: Grau de Satisfação dos Usuários}

Os princípios de diálogo previstos na parte 10 da norma ISO 9241 foram utilizados na organização do questionário de identificação do grau de satisfação dos usuários. A parte 10 da ISO-9241 trata dos princípios de diálogo: que definem os 7 princípios de projeto que segundo o comitê técnico que elaborou esta norma ISO podem levar a uma interface humano-computador ergonômica. São eles:

- Adaptabilidadeà tarefa - Um diálogoé adaptável à tarefa quando dá suporte ao usuário na realização efetiva e eficiente da tarefa. 
- Auto descrição - Um diálogo é auto descritivo quando cada passo é imediatamente compreendido através do feedback do sistema, ou quando sob demanda do usuário.

- Controle - O diálogo é controlável quando o usuário é capaz de iniciar e controlar a direção e o ritmo da interação até que seu objetivo seja atingido.

- Conformidade com as expectativas do usuário - O diálogo adapta-se às expectativas do usuário quando ele é consistente e corresponde a suas características, tais como conhecimento da tarefa, educação, experiência e convenções.

- Tolerância a erros - Um diálogo é tolerante a erros se a despeito de erros evidentes de entrada, o resultado esperado pode ser alcançado com mínimas ou nenhuma ação corretivas por parte do usuário.

- Adequação a individualização - O sistema é capaz de individualização quando a interface pode ser modificada para se adaptar as necessidades da tarefa, as preferências individuais e as habilidades dos usuários.

- Adequaçãoaoaprendizado-Osistemaéadequadoaoaprendizado quando apoia e conduz o usuário no aprendizado do sistema.

A norma explica como identificar a informação necessária a ser considerada na especificação ou avaliação de usabilidade de um computador em termos de medidas de desempenho e satisfação do usuário. Orientações sobre como descrever explicitamente o contexto de uso do produto e as medidas relevantes de usabilidade que são dadas pela norma podem na avaliação da interface de aplicativos para dispositivos móveis, foco deste estudo. Por isso, descrevem-se as características dos dispositivos móveis, cuja usabilidade será medida com a aplicação da parte 10 da ISO-9241.

\subsection{Dispositivos Móveis}

Os aplicativos são pequenos softwares instalados em sistemas operacionais de smartphones e tablets. Com a possibilidade de acessar conteúdo on-line e off-line. O mercado de aplicativos apresenta número cada vez mais expressivo de downloads e usuários, transformando atividades econômicas e sociais de maneira profunda (GOGGIN, 2006). O entanto, a usabilidade destes produtos depende da qualidade dos projetos de design. Segundo Lee et al., (2005) a usabilidade de um dispositivo móvel depende do design da interface gráfica dos dispositivos, do ambiente e do perfil do usuário.

Os dispositivos móveis são desenvolvidos com características próprias, como "Tempo de inicialização" (em aplicações de tempo crítico pode requerer um dispositivo com inicialização imediata), "Integridade de dados" (se um usuário não puder tolerar perda de dados e necessitar de armazenamento permanente, no próprio dispositivo), "Robustez/resistência" (os dispositivos móveis geralmente não são muito robustos e podem se quebrar se forrem derrubados) e "Interface com o usuário" (as características intrínsecas do dispositivo podem incapacitá-lo a desempenhar certas funções, devido à sua natureza de interface com o usuário).

Dependendo da função de uso e do ambiente o usuário escolhe o tipo de dispositivo móvel. Em ambiente normal um dispositivo móvel pode trabalhar sob as condições normais de trabalho do usuário, devendo também trabalhar em condições que dependem das condições do tempo, da luz entre outros.

A interação do usuário o dispositivo móvel depende, até certo ponto, de suas características pessoais como a facilidade de aprendizagem, conhecimento e capacidade de dominar processos tecnológicos. Portanto, a usabilidade dos dispositivos móveis não fica restrita à interface com o usuário. As características do usuário, do ambiente e dos dispositivos móveis são fatores que influenciam a interação na gestão de projetos de design. Portanto, o foco no usuário é central no processo de design, ampliando-se muito mais nos dispositivos móveis pelas suas especificidades, os aparelhos são pequenos. O design do aplicativo tem que ser pensado em como os dedos é utilizado no dispositivo, pois em um dispositivo móvel, os usuários não vão mais usar um mouse para interagir com o dispositivo. Caso os ícones de acesso ao aplicativo forem pequenos, dificulta ao usuário clicar. Antes de desenvolver o projeto é preciso entender que o tamanho da tela do aplicativo móvel é bem menor do que a de um monitor. O conteúdo tem que ser adaptado ao aparelho, bem como a resolução das imagens, controles de acesso, etc., mas o foco tem que continuar sendo no ser humano e não nos softwares e nas máquinas.

Se o conteúdo se adapta aos dispositivos móveis, os usuários podem acessar a informação de qualquer lugar independentemente do dispositivo usado. Porém, existem importantes diferenças no tipo de conteúdo que podem ser manuseados nos dispositivos móveis, como a capacidade de baixar arquivos e de visualização limitada, das capacidades técnicas destes dispositivos (janelas pequenas, falta de suporte de algumas tecnologias) e do contexto no qual o usuário recebe o conteúdo (na rua, nos transportes públicos, etc.) (GOGGIN, 2013).

As normas de usabilidade devem ser identificadas e aplicadas no início do projeto, podendo sempre ser avaliadas para melhorar as novas versões do sistema. Medir a usabilidades do que foi construído, no que se refere à experiência de uso, dá um retorno a respeito de que mudanças devem ser feitas ou quais requisitos não foram preenchidos. Apresenta-se em seguida, o estudo de caso com a aplicação da parte 10 da ISO-9241.

\section{Estudo de Caso}

Os procedimentos metodológicos adotados nesta pesquisa tiveram como foco o aplicativo Trello. Trata-se de um aplicativo online que permite gerenciar projetos e tarefas. Através de colunas personalizáveis, o usuário poderá acrescentar novas atividades e arquivos, inserir tags para facilitar sua localização posteriormente e delegar tarefas para outras pessoas. O Trello está disponível na web e em versões para Windows 8, iOS e Android 3.2.1.661. Esta ferramenta é um organizador de tarefas e eventos, inspirado na metodologia Scrum, processo de desenvolvimento para gerenciar projetos e desenvolvimento ágil de softwares (www.seomaster.com.br).

O programa dispõe de uma grande tela azul chamada 
quadro (board), onde as listas (lists) são exibidas. Cada lista define os passos de uma ação específica. As listas podem ser nomeadas, como por exemplo, como "Fazer", "Fazendo", "Revisão" e "Feito". Na figura 1 pode-se ter uma ideia de como fica um quadro com suas listas. Em cada lista ficam agrupados os cartões (cards). Cada cartão representa uma tarefa específica, como por exemplo, "Revisar artigo para o blog" (www.seomaster.com.br).

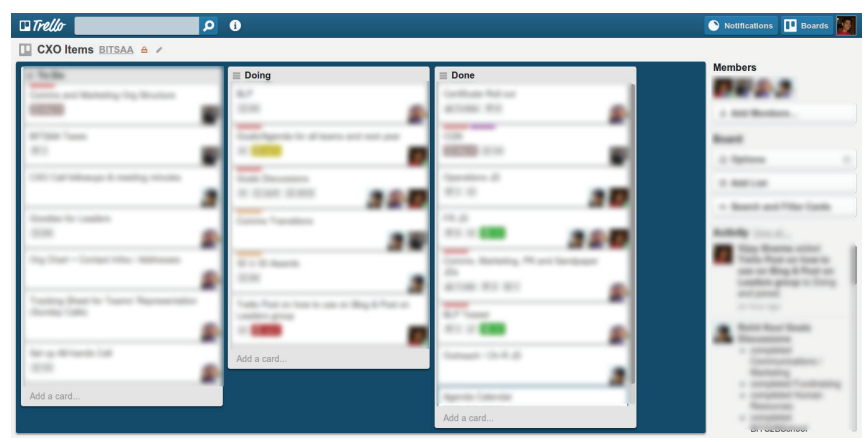

Figura 1: Tela do aplicativo Trello. Fonte - http://www.seomaster.com. br/blog/conheca-o-trello-sua-nova-ferramenta-de-organizacao.

Quando se clica em um cartão, uma nova janela é aberta e nela é possível ver os detalhes do cartão. Ali é exibido o histórico, como as listas em que ele esteve, e uma descrição feita pela pessoa responsável pela ação que ele representa. É possível criar os próprios cartões e os que são destinados à outras pessoas, podendo colocar vários membros em um mesmo cartão. Além disso, uma pessoa pode "se adicionar" em um cartão que não tenha ninguém ou que já tenha outros responsáveis. Outro artifício para diferenciar tarefas ou prioridades é a adição de etiquetas (labels) coloridas, onde cada cor pode significar um estágio ou dar uma importância diferente à ação do cartão. Este aplicativo para o sistema iOS pode se usado em celular o que facilita o trabalho durante o deslocamento do usuário (http://www.seomaster.com.br).

Etapas da pesquisa de campo: a) escolha do aplicativo; b) seleção da amostra da pesquisa; d) formulação das questões do questionário; e) envio do questionário; f) recebimento das respostas e tabulação dos dados; g) análise dos dados, segundo cada princípio de diálogo descrito na norma. A amostra da pesquisa foi composta por 6 profissionais da área de design. 0 questionário foi formulado objetivando determinar os pontos fortes e fracos do produto com base na parte 10 da ISO-9241 que define os 7 princípios de projeto que podem levar a uma interface humano-computador ergonômica. Os usuários responderam 4 perguntas para cada um dos princípios da norma.

Os gráficos a seguir apresentam a análise de satisfação dos usuários. Os dados do gráfico 1, mostra a avaliação do usuário a respeito do suporte do aplicativo para que as tarefas sejam executadas de maneira eficiente e efetiva. Segundo a maioria dos usuários (67\%) do aplicativo Trello, os recursos do sistema permitem que todas as funções necessárias à execução das tarefas são realizadas rapidamente. Dos entrevistados,
100\% destacaram a facilidade na automatização das tarefas repetitivas o que assegura a agilidade aos processos. As respostas das demais questões sobre este princípio demonstram que o aplicativo Trello não requer entrada de dados desnecessários, sendo apropriado para as necessidades do trabalho. As repostas dos usuários indicam que um dos pontos forte deste produto é a sua adequação a tarefa, conforme a primeira norma da parte 10 da ISO-9241 parte 11.

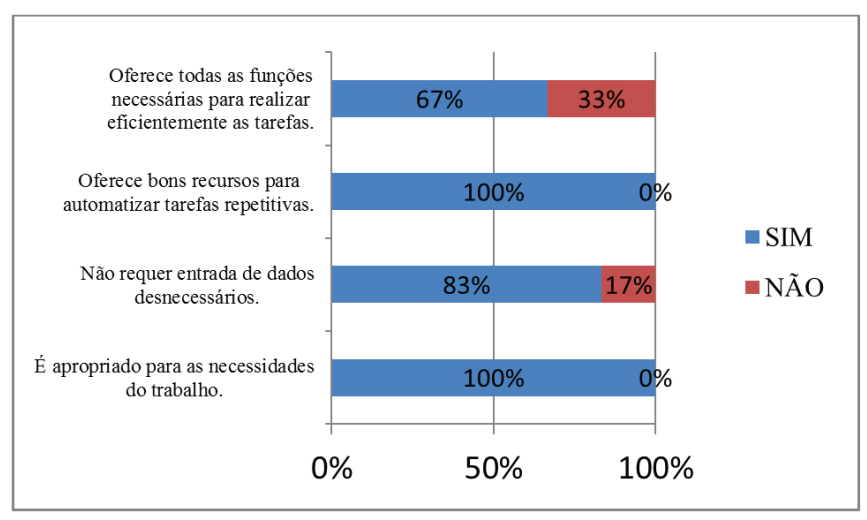

Gráfico 1: Princípio I: Adequação à Tarefa. Fonte - Resultado da Pesquisa de Campo.

O segundo princípio refere-se à avalição da auto-descrição das funções do sistema, destacando como os menus, os símbolos e as terminologias (termos técnicos) usados no diálogo são empregados no campo específico do aplicativo, de modo que ofereça explicação da função que está sendo executada e confirmação antes de efetuar a ação. Observa-se no gráfico 2 , que $67 \%$ dos participantes da pesquisa indicaram que cada passo da função, que vai sendo realizada recebe explicação compreensível quando solicitada. O principio da ISO, a autodescrição é um ponto forte, demostrando a facilidade de uso e o uso amigável. Neste princípio, apenas a questão sobre a função do aplicativo em proporcionar explicações sensíveis ao contexto automaticamente, 50\% dos participantes não consideraram um ponto forte desta ferramenta de gestão. O que significa a necessidade de modificações, que possam atender melhor esta parte do segundo princípio.

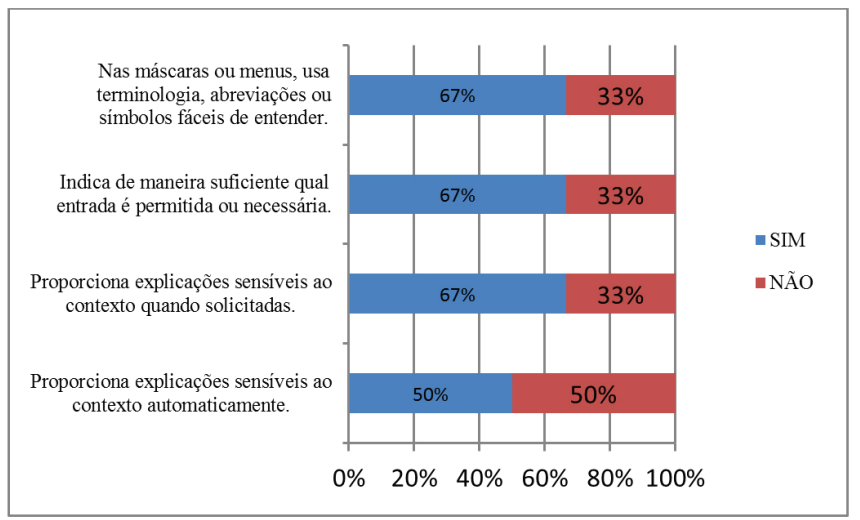

Gráfico 2: Princípio II: Auto-Descrição. Fonte - Resultado da Pesquisa de Campo. 
O princípio de Controlabilidade tem como objetivo avaliar se o sistema permite que o usuário inicie e controle a direção e o ritmo da interação. Isto significa que o usuário deve ter controle sobre o sistema, para que possa com mais liberdade realizar suas tarefas, sem necessitar de auxílio adicional. Como constatado no gráfico 3, 67\% dos respondeste registraram que este princípio é um ponto forte do aplicativo Trello, pois foi projetado de forma que o usuário possa influenciar no tipo de informação que é apresentado na tela e como pode ser apresentada. Não acarretando interrupções desnecessárias do fluxo de trabalho, como indicado por $67 \%$ dos usuários.

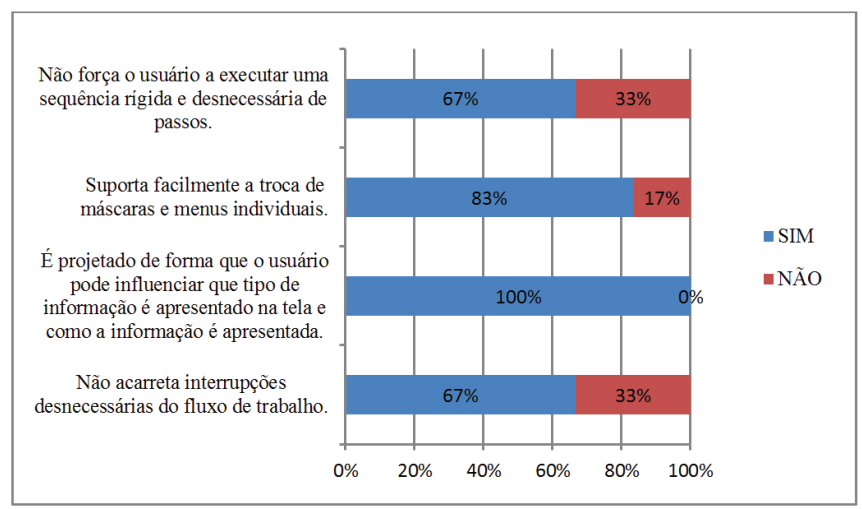

Gráfico 3: Princípio III: Controlabilidade. Fonte - Resultado da Pesquisa de Campo.

O princípio Conformidade com as Expectativas dos Usuários tem como objetivo Avaliar se o sistema é consistente e corresponde às características individuais dousuário comotarefa, conhecimento, educação, experiência e convenções usualmente aceitas. O gráfico 4, mostra que o projeto da interface do aplicativo Trello, proporciona feedback (retroalimentação ) para informar o usuário claramente a respeito das ações que podem ser revertidas antes de serem completadas. $100 \%$ dos usuários confirmam que o sistema do aplicativo foi projetado com princípio consistente e padronizado.

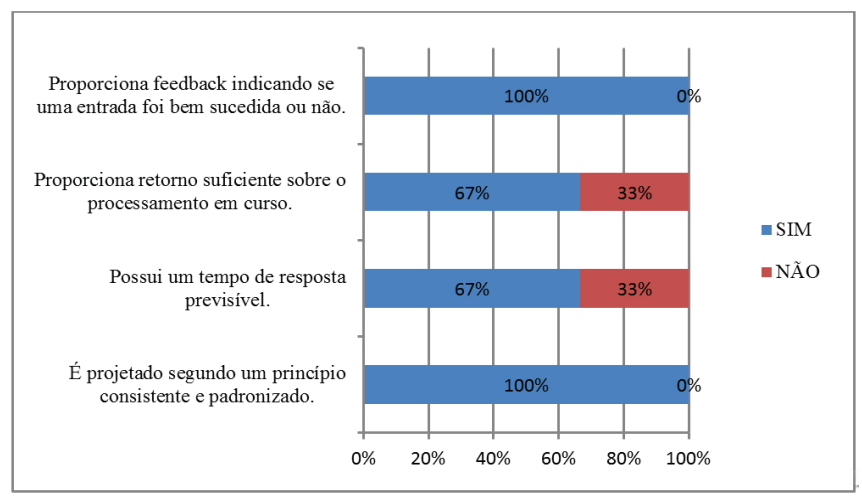

Gráfico 4: Princípio IV: Conformidade com as Expectativas dos Usuários. Fonte - Resultado da Pesquisa de Campo.

O princípio Tolerância a Erros tem como objetivo Avaliar se o sistema atinge os resultados esperados apesar de erros evidentes na entrada, requerendo nenhuma ou mínima ação corretiva por parte do usuário. Os erros durante o uso de um sistema é comum acontecer, mas segundo este princípio da ISO-9241, os erros não devem ter consequências severas. O usuário deve ser avisado imediatamente sobre o erro, para que possa reverter a ação, ou seja, desfazer o que foi feito e refazer o trabalho. As respostas dos usuários a este princípio mostra no gráfico 5, que 83\% dos usuários estão insatisfação com o sistema, pelo fato de encontrarem falha na informação dos erros e na ajuda para as devidas correções. Esteé um ponto fraco no sistema do aplicativo Trello. Esta fragilidade do sistema pode causar no usuário, insegurança e desconforto à medida que sente medo de errar a tarefa que vai ser realizada, o que implica na insatisfação do usuário. Conforme, a estruturara da usabilidade apresentada na teoria, a satisfação está diretamente ligada ao uso. O aplicativo deve proteger o seu usuário de possíveis erros e se, mesmo assim, ele ocorrer, permitir a recuperação de maneira rápida e fácil, sem prejuízo ao trabalho que está sendo realizado.

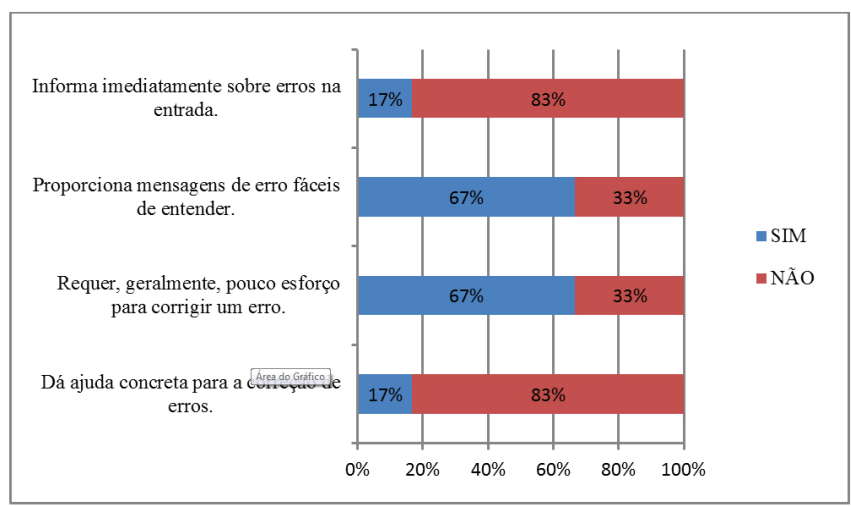

Gráfico 5: Princípio V: Tolerância a Erros. Fonte - Resultado da Pesquisa de Campo.

O princípio Suporte à Individualização tem como objetivo avaliar se o sistema é facilmente modificado de forma a adequar-se às necessidades das tarefas do usuário, preferências e experiência individuais. Constata-se no gráfico 6 , que a maioria dos respondentes da pesquisa afirmaram que o sistema dá suporte para adaptação as necessidades individuais dos profissionais na realização de outra tarefas compatíveis com o escopo de suas funções. O projeto gráfico do aplicativo Trello, com estas possibilidades está adequado a usuários iniciantes.

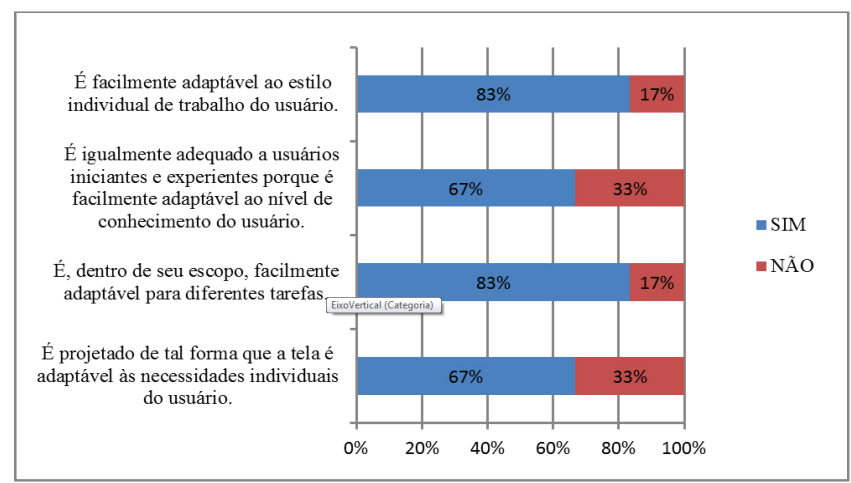

Gráfico 6: Princípio VI: Suporte à Individualização. Fonte - Resultado da Pesquisa de Campo. 


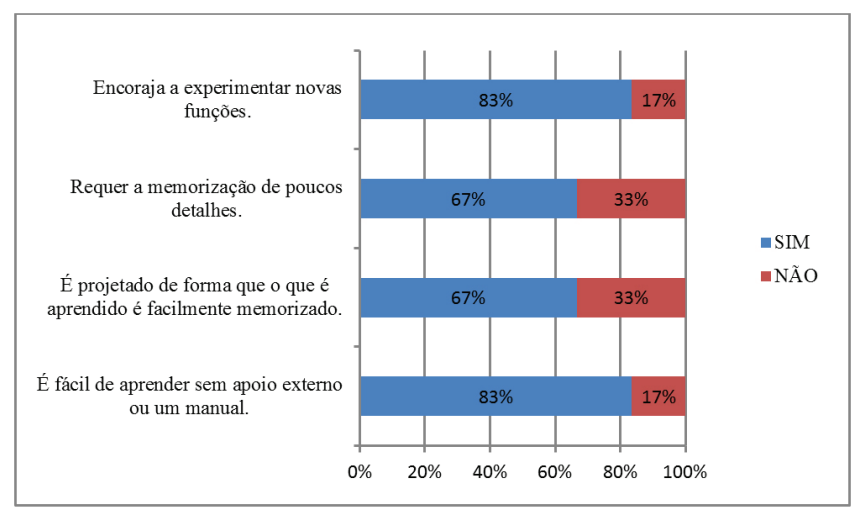

Gráfico 7: Princípio VII: Adequação ao Aprendizado. Fonte - Resultado da Pesquisa de Campo.

Oprincípio Adequação ao Aprendizado tem como objetivo avaliar se o sistema suporta e guia o usuário no aprendizado do uso do sistema. Conforme resultados da pesquisa de campo no gráfico 7, a adequação ao aprendizado é um ponto forte do sistema Trello. Como ele é fácil de aprender, mesmo sem auxílio externo ou manual, os usuários ficam interessados em experimentar suas funções. Além disso, permite fácil memorização do que foi trabalhado. Está, portanto, adequado ao aprendizado, atendo aos princípios da ISO ISO-9241.

A pesquisa de campo aplicada com usuários do aplicativo Trello foi realizada com base nas orientações da usabilidade, mas especificamente da sua parte 11, que descreve os objetivos de 7 princípios que levam os usuários a alcançar seus objetivos de maneira satisfatória. Esta satisfação é medida: pelo alcance da eficácia na realização dos objetivos; pela eficiência dos recursos do sistema para atingir estes objetivos e pela satisfação por conseguir de modo fácil usar todas as funções que o sistema oferece. A satisfação do usuário desenvolve um sentimento de progresso com a execução de seus objetivos.

\section{Conclusão}

Os resultados da pesquisa mensuraram a usabilidade do aplicativo Trello, considerando os requisitos normatizados pela ISO 9241-11 (ABNT, 2008). De acordo com a análise dos resultados a usabilidade do sistema foco desta pesquisa, atingiu os critérios de eficácia, eficiência e satisfação.

Foi constatado com o resultado da pesquisa, que o aplicativo teve apenas como ponto fraco, o fato dos usuários encontrarem falha na informação dos erros e na ajuda para as devidas correções. Esta questão causou insatisfação, principalmente ao usuário iniciante, que ficam inseguros quando cometem erros e demoram em corrigir, ou perder parte do trabalho. O sistema de diálogo deve prevenir o usuário de qualquer erro, que devem ser explicados de forma a auxiliar o usuário na correção dos erros.

Como o aplicativo Trello está disponível na web pode ser usado em dispositivos móveis, como celulares e tabletes, facilitando o trabalho dos usuários em qualquer lugar onde estiverem, bem como na comunicação com outras pessoas que façam parte da equipe de projeto.

Diante de todos os resultados obtidos, concluiu-se que a usabilidade e os princípios da norma ISO 9241-11 podem ser aplicadas como recomendações gerais, no desenvolvimento de projeto de design de aplicativos, considerando as expectativas dos usuários e a sua satisfação durante o uso e a interação com o produto.

\section{Referência}

ABNT - ASSOCIAÇÃO BRASILEIRA DE NORMAS TÉCNICAS. NBR 9241-11 (2002) Requisitos ergonômicos para trabalho de escritório com computadores: parte 11 - orientação sobre usabilidade. Rio de Janeiro: ABNT.

GOGGIN, Gerard. (2013). Cell Phone Culture. Mobile technology in everyday lifeNew York, Routdlege.

ISO 9241, Parte 11 (2011). Orientações sobre Usabilidade. Associação Brasileira de Normas Técnicas. ABNT.

LEE, V.; SCHINEIDER, H. \& SCHELL, R. (2005). Aplicações móveis: arquitetura, projeto e desenvolvimento. São Paulo: Pearso.

NORMAN, D. A. (2002). The Design of Everyday Things. Basic Books.

PREECE, J; ROGERS, Y; SHARP, H. (2008). Design de Interação: Além da interação homem computador. Porto Alegre: Bookman.

SOUZA, C.S. de; et al. (1999). Projeto de interfaces de usuário: perspectivas cognitiva e semiótica. In: XIX Congresso da Sociedade Brasileira de Computação, 1999, Rio de Janeiro. Anais... Rio de Janeiro.

The Web and Mobile Devices: http://www.w3.org/Mobileacesso em 10 de fevereiro de 2015. Portio Research (2013) Mobile Applications Futures 2013-2017

http://www.portioresearch.com/en/major-reports/currentportfolio/mobile-applications-futures-2013-2017.aspx. Acesso em 20 de Março de 2015. 